Journal of Applied Pharmaceutical Science Vol. 6 (07), pp. 094-099, July, 2016

Available online at http://www.japsonline.com

DOI: 10.7324/JAPS.2016.60714

ISSN 2231-3354 (cc)) EY-NC-SA

\title{
Ameliorative potential of Aframomum melegueta extract in cadmium- induced hepatic damage and oxidative stress in male Wistar rats
}

\author{
Babatunji Emmanuel Oyinloye $^{1^{*}}$, Basiru Olaitan Ajiboye ${ }^{1}$, Oluwafemi Adeleke Ojo ${ }^{1}$, Habiba M. Musa ${ }^{1}$, Sunday Amos \\ Onikanni ${ }^{1}$, Abiodun Ayodele $\mathrm{Ojo}^{2}$ \\ ${ }^{1}$ Biochemistry Unit, Department of Chemical Sciences, College of Sciences, Afe Babalola University, PMB 5454, Ado-Ekiti 360001, Nigeria Ado Ekiti, \\ Nigeria. ${ }^{2}$ Chemistry Unit, Department of Chemical Sciences, College of Sciences, Afe Babalola University, PMB 5454, Ado-Ekiti 360001, Nigeria Ado \\ Ekiti, Nigeria.
}

\begin{tabular}{|c|c|}
\hline ARTICLE INFO & ABSTRACT \\
\hline Article history: & \multirow{8}{*}{$\begin{array}{l}\text { The present study was undertaken to explore the ameliorative potential of aqueous extract of Aframomum } \\
\text { melegueta (AM) on cadmium-induced hepatic damage in rats. Toxicity was induced by daily administration of } \\
200 \mathrm{mg} / \mathrm{L} \text { cadmium: } \mathrm{Cd}\left(\mathrm{Cd} \text { as } \mathrm{CdCl}_{2}\right) \text { in the animals' main drinking water for } 21 \text { days. Lipid peroxidation } \\
\text { (LPO), catalase (CAT), glutathione peroxidase (GPx) and superoxide dismutase (SOD) activities were } \\
\text { determined in the liver while total protein, albumin, direct bilirubin and total bilirubin concentration as well as } \\
\text { alanine aminotransferase (ALT) and aspartate aminotransferase (AST) activities were monitored in the serum } \\
\text { and histological examination was carried out. Exposure to cadmium resulted in various alterations in all the } \\
\text { evaluated parameters. Treatment with AM ( } 200 \text { or } 400 \mathrm{mg} / \mathrm{kg} \text { bw) extract showed a significant (P <0.05) } \\
\text { reversal effect that mitigated the deleterious effect of cadmium. Results of the histological examination also } \\
\text { support the above findings. The results suggest that aqueous extracts of } A \text {. melegueta when administered orally, } \\
\text { could ameliorate cadmium-associated oxidative stress in male Wistar rats in a dose dependant manner via its } \\
\text { free radical-scavenging mechanism which could be linked to the synergetic effects between the bioactive } \\
\text { constituents present in the extract. }\end{array}$} \\
\hline Received on: $12 / 04 / 2016$ & \\
\hline Revised on: 18/05/2016 & \\
\hline Accepted on: 11/06/2016 & \\
\hline Available online: $28 / 07 / 2016$ & \\
\hline Key words: & \\
\hline Aframomum melegueta; & \\
\hline $\begin{array}{l}\text { Antioxidant; aqueous extract; } \\
\text { cadmium toxicity; } \\
\text { hepatoprotective. }\end{array}$ & \\
\hline
\end{tabular}

\section{INTRODUCTION}

Cadmium is ubiquitous in nature and to a great extent; it is concentrated in the food chain due to its high soluble nature compared to other toxic heavy metals, it is not degradable; consequently it is easily transported from soil to plants which animals and humans largely depend on for survival (Gallagher $e t$ al., 2010; Del Pino et al., 2014). Some of the routes of cadmium intake involve the lungs, intestines and skin. There are no exact mechanism for the excretion of cadmium in humans, so it bioaccumulates in various tissues especially kidneys, lungs, pancreas and liver (Haidry and Malik, 2014; Rahman, 2007); where it contributes significantly in the pathogenesis of oxidative

\footnotetext{
* Corresponding Author

Babatunji Emmanuel Oyinloye, Biochemistry Unit, Department of

Chemical Sciences, College of Sciences, Afe Babalola University, PMB

5454, Ado-Ekiti 360001, Nigeria Ado Ekiti, Nigeria.

Email: babatunjioe@abuad.edu.ng
}

dysfunction in various animal and human organs notably the kidney, brain, testes, heart and liver (Sarkar et al., 2013). Oxidative stress resulting from excessive generation of free radicals, especially reactive oxygen species (ROS) is the basic mechanism of cadmium toxicity. However, cadmium is unable to induce ROS generation directly since it's a non-fenton metal (Haidry and Malik, 2014). It induces oxidative stress indirectly via displacement of redox-active metals and makes use of their transport systems. It also depletes redox scavengers and inhibits antioxidant enzymes as well as electron transport chain (ETC) resulting in mitochondrial damage (Nair et al., 2013). In the liver, cadmium is taken into the hepatocytes where it binds to metallothioneins (MTs), glutathione (GSH) and other proteins or peptides and form new complexes. Hydroxyl radical is the most reactive and damaging radical formed; which initiates cellular damages and lipid peroxidation (LPO) even at extremely small concentrations (Haidry and Malik, 2014; Abdel Moneim et al., 2014; Prabu et al., 2012; Mitra et al., 2012; Nair et al., 2013). The 
global health impact and socioeconomic burden associated with oxidative stress arising from various alteration patterns in hepatic antioxidant status is of great concern for researchers in the last few years. Damaging consequences of oxidative stress can be prevented by employing medicinal plants and spices containing natural antioxidants that can inhibit the generation of free radicals and prevent/delay progressions in oxidative stress and damage, thereby conferring protection to the liver (Flora, 2009).

Aframomum melegueta (Alligator pepper) is one of such plants having both medicinal and nutritive values. It is popularly used as herbal remedy against a wide range of ailments, both in Nigeria and several other countries of the world. Detailed phytochemical screening carried out revealed that aqueous extract of A. melegueta seeds contains hepatoprotective and free radical scavengers such as alkaloids, phenols, flavonoids, saponins and tannins in appreciable quantities (Nwozo and Oyinloye, 2011). The present work demonstrates that aqueous extract of $A$. melegueta at a dose of 200 or $400 \mathrm{mg} / \mathrm{kg}$ bw possess hepatoprotective and antioxidative potential to ameliorate cadmium induced toxicity and oxidative stress in animal models.

\section{MATERIALS AND METHODS}

\section{Chemicals}

All the chemicals and reagents were purchased from Sigma Chemical (St Louis, MO, USA) and Merck (Germany). All kits (Randox assay kits) were purchased from ABJ Chemicals (Lagos, Nigeria).

\section{Plant material and extract preparation}

Fruits of Aframomum melegueta were purchased from Bodija market (Nigeria). Identification and authentication were previously carried out by Nwozo and Oyinloye, 2011. One kilogram of seeds from air-dried fruits was washed with distilled water and air-dried. The dried seeds were pulverized into uniform powder using an electric blender $\left(25-28{ }^{\circ} \mathrm{C}\right)$. The pulverized seed was extracted by maceration in distilled water $(200 \mathrm{~g} / 1000 \mathrm{ml})$ for 72 hours. The aqueous extract was filtered and the filtrate was freeze-dried to yield a yellowish brown extract. The lyophilized extract was carefully scraped (into a clean sample bottle and stored in a refrigerator at $4{ }^{\circ} \mathrm{C}$ for further use. Portions of the lyophilized extract used for this experiment were weighed and reconstituted in distilled water daily, just before administration to the animals.

\section{Animals and experimental design}

Twenty-four male albino (Wistar strain) rats were obtained from the Animal house of the Department of Biochemistry, College of Sciences, Afe Babalola University, weighing between $103 \mathrm{~g}$ and $157 \mathrm{~g}$. The animals were allowed access to feed and water ad libitum for a period of fourteen days, for their acclimatization prior to the commencement of the experiment. The animals were kept in well ventilated cages at room temperature $\left(28^{\circ}-30^{\circ} \mathrm{C}\right)$, and under controlled light cycles (12 h light/12 h dark). All procedures were carried out in accordance with the conventional guidelines of the National Institutes of Health (Maryland, USA) for experimentation with animals and protocol approved by the Institutional Animal Care and Use Committee of Afe Babalola University. The rats were randomly distributed into four groups of six animals each. Group 1: served as the control and consisted of animals fed with standard rat pellet and distilled water only. Group 2: consisted of animals fed with standard rat pellet and cadmium only (cadmium control). Group 3 consisted of animals fed with standard rat pellet, cadmium and A. melegueta extract (200 mg/kg), while Group 4 consisted of animals fed with standard rat pellet, cadmium and $A$. melegueta extract (400 mg/kg). A. melegueta (AM) extracts (200 and $400 \mathrm{mg} / \mathrm{kg}$ bw) was given orally by gavage for 21 days. Cadmium was administered daily $\left(200 \mathrm{mg} / \mathrm{L} \mathrm{Cd}\right.$ as $\left.\mathrm{CdCl}_{2}\right)$ in the animals' (Groups 2, 3 and 4) main drinking water per day for 21 days to induce toxicity (Layachi and Kechrid, 2012).

\section{Preparation of blood and tissue homogenates for biochemical analyses and histological examination}

The experiment lasted for 21 days, on day 22th; the animals were sacrificed 24 hours after the last dose. Blood samples were collected and allowed to coagulate at room temperature. The clear, non-haemolysed supernatant sera were quickly removed and stored at $-20{ }^{\circ} \mathrm{C}$ for subsequent analysis. Liver samples were quickly excised and washed in ice-cold $1.15 \% \mathrm{KCl}$ solution, dried using filter paper and weighed. They were then homogenized in 4 volumes of $56 \mathrm{mM}$ Tris/ $\mathrm{HCl}$ buffer $(\mathrm{pH} \mathrm{7.4)}$ containing $1.15 \%$ potassium chloride and centrifuged at $10000 \times g$ for $15 \mathrm{~min}$. The supernatant was collected and stored at $-20{ }^{\circ} \mathrm{C}$ until needed for assays. Small pieces of liver sections were fixed in $10 \%$ formal saline and processed for paraffin embedding. Sections of 4-6 $\mu \mathrm{m}$ thickness were cut and stained with hematoxylin and eosin $(\mathrm{H}$ and E) and observed under light microscope for histopathological changes (Lilli, 1965).

\section{Biochemical assays}

Lipid peroxidation was determined by measuring the thiobarbituric acid reactive substances (TBARS) produced during lipid peroxidation by following the method of Varshney and Kale (1990). Catalase (CAT) activity was determined by adopting the method described by Sinha, 1972. The level of SOD activity was determined by the method of Misra and Fridovich (1972). Glutathione peroxidase (GPx) was assayed by the method of Hafeman et al., 1974. Serum total proteins concentration was determined according to the method of Henry (1964) while albumin concentration was determined in serum according to the method of Doumas et al., (1971). Direct bilirubin concentration was also determined in serum according to the method of Walter and Gerade (1970) while total bilirubin was determined according to Schmidt and Eisenburg, 1975. Activities of serum alanine aminotransferase (ALT) and aspartate aminotransferase (AST) were determined according to the method of Reitman and Frankel (1957), using commercially available diagnostic kits (Randox Laboratories, UK). 


\section{Statistical analysis}

The values were presented as means \pm SD of different groups. Differences between the mean values were estimated using one-way analysis of variance (ANOVA). The results were considered statistically significant when $\mathrm{p}<0.05$.

\section{RESULTS}

Effects of cadmium exposure and Aframomum melegueta on total protein, albumin, direct bilirubin and total bilirubin

The effects of cadmium exposure and A. melegueta (200 or $400 \mathrm{mg} / \mathrm{kg} \mathrm{bw}$ ) treatment on total protein, albumin, direct bilirubin and total bilirubin are depicted in Figure 1. Serum total protein and albumin levels were decreased significantly $\mathrm{p}<0.05$ in cadmium-administered rats as compared with the control, whereas significant $\mathrm{p}<0.05$ increases were recorded in levels of serum total and direct bilirubin in cadmium-treated rats compared with the control. The treatment of cadmium-administered rats with $A$. melegueta (200 or $400 \mathrm{mg} / \mathrm{kg}$ bw) ameliorate this changes in a dose dependent manner.

\section{Effects of cadmium exposure and Aframomum melegueta on aspartate aminotransferase (AST) and alanine aminotransferase (ALT) activities}

Figure 2 shows the effects of cadmium-exposure as well as the preventive effects A. melegueta (200 or $400 \mathrm{mg} / \mathrm{kg} \mathrm{bw}$ ) on serum aminotransferase activities. Exposing animals to cadmium resulted in severe hepatotoxicity, as indicated by the significant $\mathrm{p}$ $<0.05$ elevation of serum AST and ALT activities compared with the control animals. Consistent with these modifications, in a dose dependent manner, administration of A. melegueta prevented the elevations observed and restored the actives of AST and ALT near normal levels when compared with the control animals.

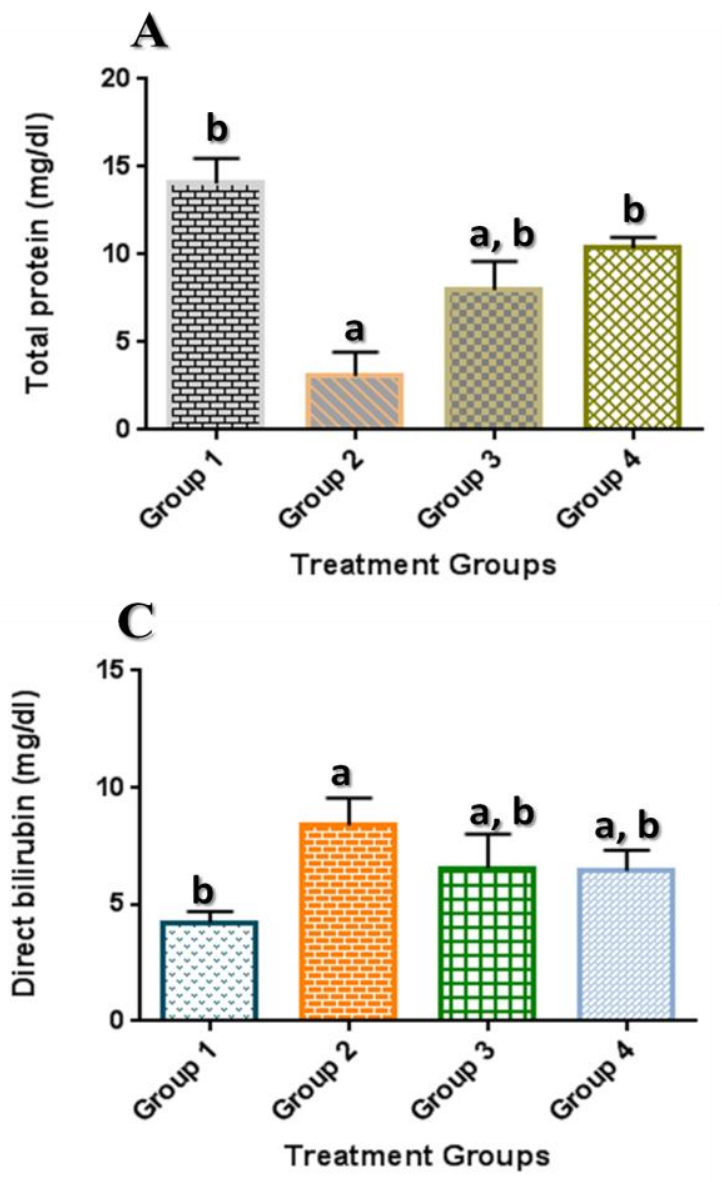

B
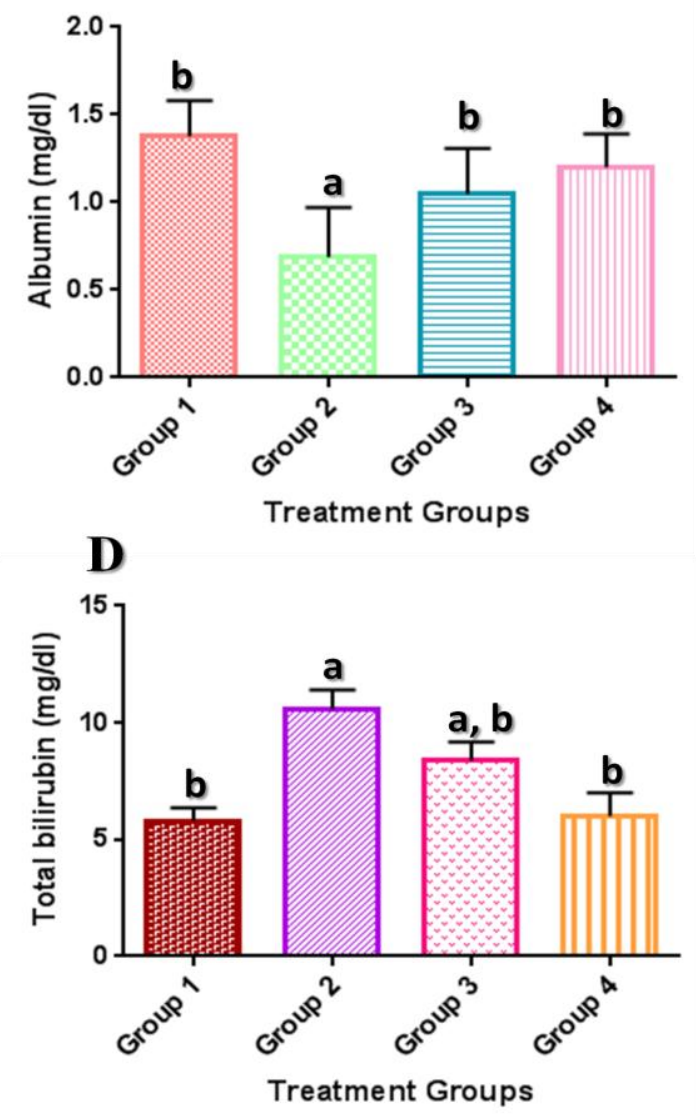

Fig. 1: Effects of cadmium exposure on total protein, albumin, direct bilirubin and total bilirubin. Values are mean of six animals \pm SD. ${ }^{\text {a }}$ The mean is significantly different compared to control at $\mathrm{P}<0.05$, and ${ }^{\mathrm{b}}$ mean is significantly different compared to cadmium-only group. 

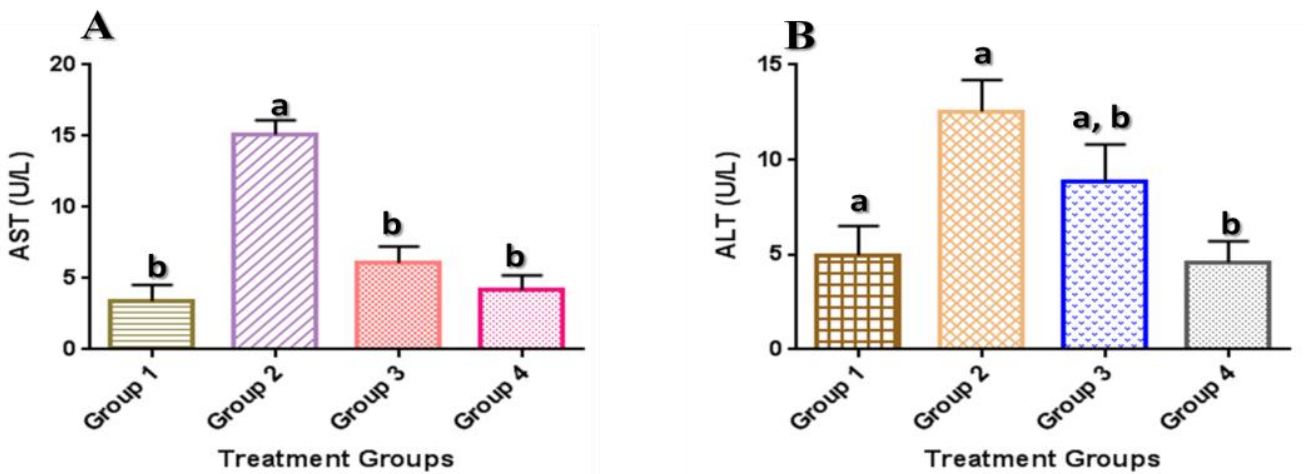

Fig. 2: Effects of cadmium exposure on aspartate aminotransferase (AST) and alanine aminotransferase (ALT) activities. Values are mean of six animals \pm SD. ${ }^{\text {a }}$ The mean is significantly different compared to control at $\mathrm{P}<0.05$, and ${ }^{\mathrm{b}}$ mean is significantly different compared to cadmium-only group.
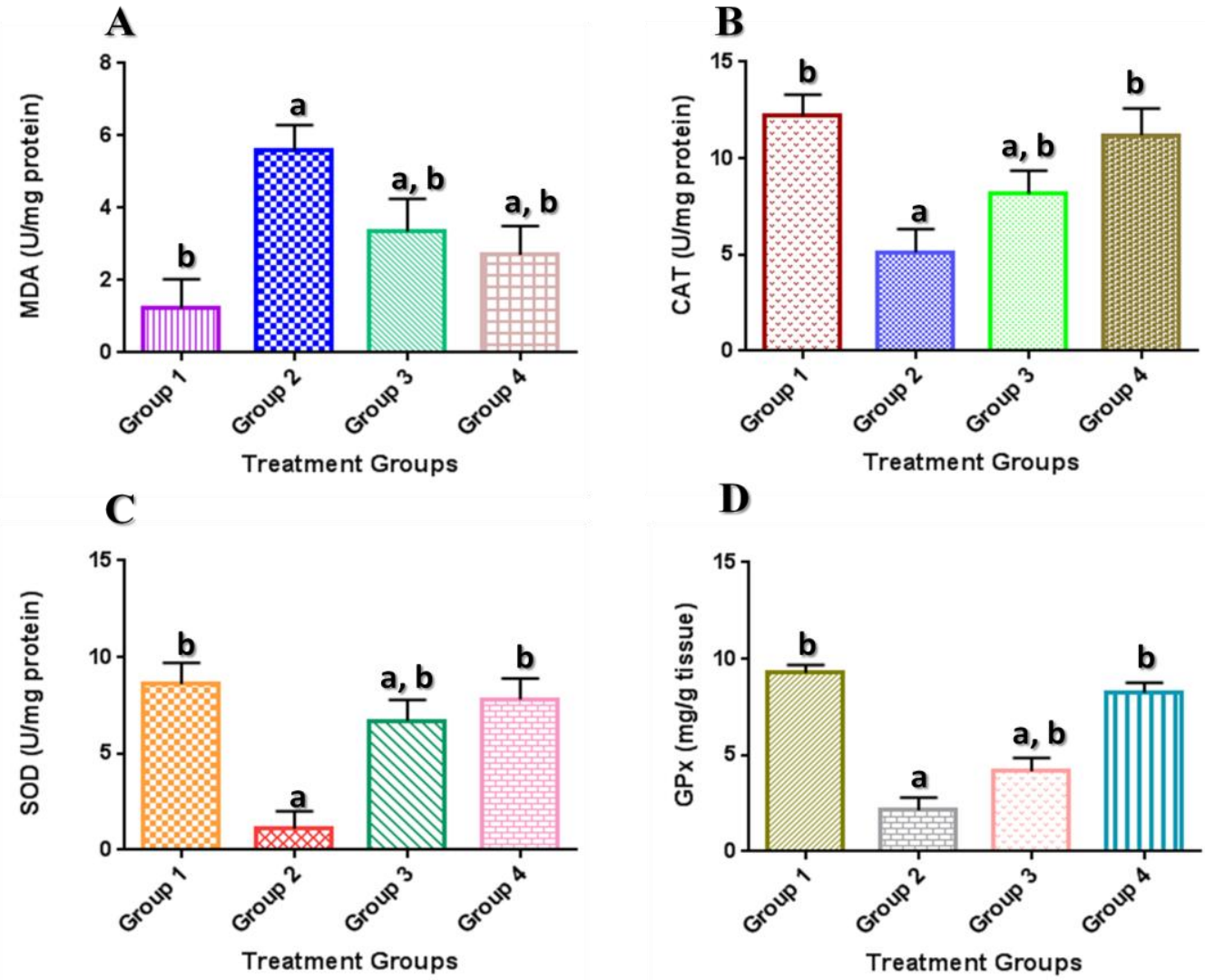

Fig. 3: Effects of cadmium exposure on lipid peroxidation (LPO), catalase (CAT), glutathione peroxidase (GPx) and superoxide dismutase (SOD). Values are mean of six animals $\pm \mathrm{SD}$. ${ }^{\mathrm{a}}$ The mean is significantly different compared to control at $\mathrm{P}<0.05$, and ${ }^{\mathrm{b}}$ mean is significantly different compared to cadmium-only group.

\section{Effects of cadmium exposure and Aframomum melegueta on lipid peroxidation (LPO), catalase (CAT), glutathione peroxidase (GPx) and superoxide dismutase (SOD)}

The protective role of $A$. melegueta on cadmium-induced oxidative liver injury is presented on Figure 3. A significant $p$ $<0.05$ increase of MDA content associated with a corresponding and concomitant reduction in the activities of catalase, superoxide dismutase and glutathione peroxidase was witnessed in the hepatic tissue homogenate of rats exposed to cadmium. Administration $A$. melegueta (200 or $400 \mathrm{mg} / \mathrm{kg}$ bw) significantly p $<0.05$ mitigate and reversed the elevated MDA levels as well as significantly $\mathrm{p}<0.05$ ameliorating the activities of catalase, superoxide dismutase and glutathione peroxidase in hepatic tissue homogenate of rats exposed to cadmium compared with the control animals.

\section{Histological examination of liver sections}

Histological examinations revealed that cadmium-exposure resulted in severe hepatic damage as indicated by degeneration of hepatocytes associated with periportal hepatic necrosis as well as cellular infiltration by mononuclear cells and fatty infiltration. $A$. melegueta treated rats, however, showed marked improvements in the degree of various alteration patterns as presented in Figure 4. 

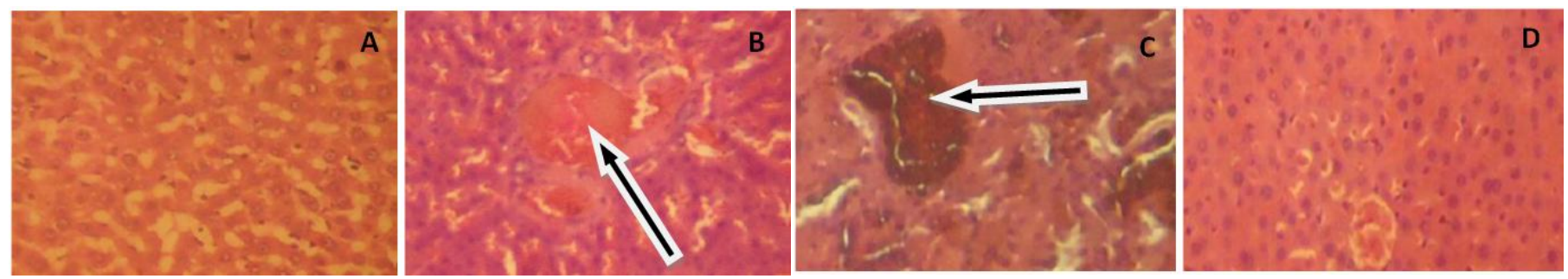

Fig. 4: Histological assessment of liver sections stained with hematoxylin and eosin ( $\times 400)$. (A) Group 1 (Control): showing no lesions or abnormalities; (B) Group 2 (cadmium alone): showing severe hepatic damage associated with cellular infiltration by mononuclear cells and fatty infiltration; (C) Group 3 (200 $\mathrm{mg} / \mathrm{kg} \mathrm{bw}$ ): showing mild degeneration of hepatocytes with periportal hepatic necrosis; (D) Group 4 (400 $\mathrm{mg} / \mathrm{kg}$ bw): showing marked improvements in the degree of various alteration patterns.

\section{DISCUSSION}

Cadmium (Cd), a non-fenton metal; is an important environmental pollutant present in soil, water, air and food. Its intracellular accumulation induces oxidative stress leading to hepatocellular damage via displacement of redox-active metals, depletion of redox scavengers, inhibition of anti-oxidant enzymes and inhibition of the electron transport chain resulting in mitochondrial damage (Nair et al., 2013; Adiele et al., 2012; Patra et al., 2011). In the present study, the significant decrease in the serum total protein and albumin of animals exposed to cadmium can be attributed to impairment in hepatocyte functions causing decreased cytochrome P-450 activity and inhibition in protein metabolism in the liver (Ibiam et al., 2013; Asagba, 2010). Whereas, the increased serum level of direct bilirubin and total bilirubin in the present study is a clear indication of hepatic dysfunction which correlates with the oxidative damage in the liver due to oxidative stress (Renugadevi and Prabu, 2010; Kowalczyk et al., 2003). Administration of AM extract showed a significant reversal effect, which is in agreement with the result from similar studies (Zhang et al., 2015; Elgaml and Hashish, 2014).

The significant elevation witnessed in serum transaminases activity (AST and ALT) clearly indicates the loss of cellular integrity and the leakage of hepatic membrane. Hepatocellular injury associated with Cd-exposure is well established in literature (Baba et al., 2013; Lu et al., 2013). Both aminotransferases (AST and ALT) are mainly concentrated in the liver; ALT is localized solely in the cytoplasm, whereas AST is present both in the cytosol and mitochondria of hepatocytes (Haidry and Malik, 2014). Interestingly, the up-regulation of AST and ALT activities due to cadmium exposure was significantly declined following the concomitant administration of AM extract (200 or $400 \mathrm{mg} / \mathrm{kg} \mathrm{bw}$ ). The ability of AM extracts to ameliorate the elevated levels of AST and ALT, also confirms its protective role.

Furthermore, cadmium interference with cellular components led to increased generation of free radicals especially, reactive oxygen species (ROS) in Cd-exposed rats. This was evident by the noticeable elevation witnessed in the levels of lipid peroxides in liver. This finding is consistent with previous studies that have demonstrated that $\mathrm{Cd}$-exposure was associated with elevation of thio-barbituric acid reactive substances (TBARS) in the liver (Ashour, 2014; Prabu et al., 2012; Srinivasan and Ramprasath, 2012). The disrupted LPO level was alleviated by administration of AM extract. Lipid peroxidation is one of the key manifestations of oxidative damage and has been found to play an essential role in the toxicity of many xenobiotics. $\mathrm{Cd}$ may induce damage directly by causing conformational changes of bio-molecules or modify specific binding sites. Added to this, $\mathrm{Cd}$ indirectly induces cellular damage; this is associated with metal driven generation of free radicals involving superoxide, hydroxyl radicals or nitric oxide, hydrogen peroxide and/or endogenous oxidants (Meena et al., 2014; Ognjanovic et al., 2008).

The data obtained in our study confirmed that $\mathrm{Cd}$ exposure diminished the enzymatic antioxidant status in the liver. It has been shown that various antioxidants and antioxidant defense systems protect cells from $\mathrm{Cd}$-induced toxicity (Ognjanovic et al., 2008). Generally, alteration in the antioxidant defense system enhances lipid peroxidation and oxidative stress. This defense system includes the enzymes SOD, catalase, glutathione peroxidase, glutathione-s-transferase as well as glutathione, which usually protect the cell against oxidative damage (Roopha and Padmalatha, 2012). Treatment with AM extract significantly restored liver CAT, SOD and GPx activities. These results were confirmed by the results obtained from the histopathological assessment of the liver which revealed that $\mathrm{Cd}$ exposure stimulated hepatocellular injuries. In conclusion, oral administration of aqueous extracts of Aframomum melegueta could provide significant protection against cadmium-induced toxicity in male Wistar rats in a dose dependant manner via its free radicalscavenging activities. Therefore, in alleviating cadmiumassociated oxidative stress; A. melegueta could be a promising nutritional-supplement.

Conflict of Interest: The authors declare that there is no conflict of interest.

\section{REFERENCES}

Abdel Moneim AE, Bauomy AA, Diab MM, Shata MT, AlOlayan EM, El-Khadragy MF. The protective effect of Physalis peruviana L. against cadmium-induced neurotoxicity in rats. Biol Trace Elem Res, 2014; 160: 392-99. 
Adiele RC, Stevens D, Kamunde C. Differential inhibition of electron transport chain enzyme complexes by cadmium and calcium in isolated rainbow trout (Oncorhynchus mykiss) hepatic mitochondria. Toxicol Sci, 2012; 127: 110-19.

Asagba S. Alteration in the activity of oxidative enzymes in the tissues of male wistar albino rats exposed to cadmium. Int J Occup Med Environ Health, 2010; 23: 55-62.

Ashour TH. Preventative effects of caffeic acid phenyl ester on cadmium intoxication induced hematological and blood coagulation disturbances and hepatorenal damage in rats. ISRN Hematology, 2014: 764754 .

Baba H, Tsuneyama K, Yazaki M, Nagata K, Minamisaka T, Tsuda T, Nomoto K, Hayashi S, Miwa S, Nakajima T, Nakanishi Y, Aoshima K, Imura J. The liver in itai-itai disease (chronic cadmium poisoning): pathological features and metallothionein expression. Mod Pathol, 2013; 26: 1228-34.

Del Pino J, Zeballos G, Anadon MJ, Capo MA, Díaz MJ, García J, Frejo MT. Higher sensitivity to cadmium induced cell death of basal forebrain cholinergic neurons: A cholinesterase dependent mechanism. Toxicology, 2014; 325:151-59.

Doumas BT, Watson WA, Biggs HG. Determination of serum albumin. J Clin Chem Acta, 1971; 31:87-89.

Elgaml SA, Hashish EA. Clinicopathological studies of Thymus vulgaris Extract Against Cadmium Induced Hepatotoxicity in Albino Rats. Global J Pharmacol, 2014; 8: 501-09.

Flora SJ. Structural, chemical and biological aspects of antioxidants for strategies against metal and metalloid exposure. Oxid Med Cell Longev, 2009; 2: 191-206.

Gallagher CM, Chen JJ, Kovach JS. Environmental cadmium and breast cancer risk. Aging (Albany NY), 2010; 2: 804.

Hafeman DG, Sundae RA, Houestra WG. Effect of dietary selenium on erythrocyte and liver glutathione peroxidase in the rat. J Nutr, 1974; 104:580-87.

Haidry MT, Malik A. Hepatoprotective and Antioxidative Effects of Terminalia Arjunaagainst Cadmium Provoked Toxicity in Albino Rats (Ratus Norvigicus). Biochem Pharmacol, 2014; 3: 130.

Henry RJ. 1964. Clinical Chemistry, Principles and Technics, 2nd Edition, Harper and Row. P.525,1974.

Ibiam AU, Ugwuja EI, Ejeogo C, Ugwu O. Cadmium-Induced Toxicity and the Hepatoprotective Potentials of Aqueous Extract of Jessiaea Nervosa Leaf. Adv Pharm Bull, 2013; 3: 309.

Kowalczyk E, Kopff A, Fijalkowski P, Kopff M, Niedworok J, Blaszczyk J, Kêdziora J, Tyslerowicz P. Effect of anthocyanins on selected biochemical parameters in rats exposed to cadmium. Acta Biochimica Polonica, 2003; 50: 543-48.

Layachi N, Kechrid Z. Combined protective effect of vitamins $\mathrm{C}$ and $\mathrm{E}$ on cadmium induced oxidative liver injury in rats. Afr $\mathrm{J}$ Biotechnol, 2012; 11(93): 16013-020.

Lilli RD. London: McGraw Hill Book Company; 1965. Histopathologic Technique and Practical Biochemistry.

Lu Q, Lei YX, He CC, Lei ZN. Blood translation elongation factor-1 $\delta$ is a novel marker for cadmium exposure. Int $\mathrm{J}$ Mol Sci, 2013; 14: 5182-97.

Meena BM, Divya K, Haseena BSK, Sailaja G, Sandhya D, Thyagaraju K. Evaluation of Genotoxic and Lipid Peroxidation Effect of Cadmium in Developing Chick Embryos. J Environ Anal Toxicol, 2014; 4: 238 .

Misra HP, Fridovich I. The role of superoxide anion in the autoxidation of epinephrine and a simple assay for superoxide dismutase. J Biol Chem, 1972; 247: 3170-75.
Mitra E, Ghosh AK, Ghosh D, Mukherjee D, Chattopadhyay A, Dutta S, Pattari SK, Bandyopadhyay D. Protective effect of aqueous curry leaf (Murraya koenigii) extract against cadmium-induced oxidative stress in rat heart. Food Chem Toxicol, 2012; 50: 1340-53.

Nair AR, DeGheselle O, Smeets K, Van Kerkhove E, Cuypers A. Cadmium-induced pathologies: where is the oxidative balance lost (or not)? Int J Mol Sci, 2013; 14: 6116-43.

Nwozo SO, Oyinloye BE. Hepatoprotective effect of aqueous extract of Aframomum melegueta on ethanol-induced toxicity in rats. Acta Biochim Pol, 2011; 58: 355-58.

Ognjanovic BI, Markovic SD, Pavlovic SZ, Zikic RV, Stajn AS, Saicic ZS. Effect of chronic cadmium exposure on antioxidant defense system in some tissues of rats: protective effect of selenium. Physiol Res, 2008; 57: 403

Patra RC, Rautray AK, Swarup D. Oxidative Stress in Lead and Cadmium Toxicity and Its Amelioration. Vet Med Int, 2011; 1:9-15.

Prabu, SM, Muthumani M, Shagirtha K. Protective effect of Piper betle leaf extract against cadmium-induced oxidative stress and hepatic dysfunction in rats. Saudi J Biol Sci, 2012; 19: 229-39.

Rahman K. Studies on free radicals, antioxidants, and cofactors. Clin Interv Aging, 2007; 2: 219-36.

Reitman S, Frankel S. A colorimetric method for the determination of serum glutamic oxalacetic and glutamic pyruvic transaminases. Am J Clin Pathol, 1957; 28: 56-63.

Renugadevi J, Prabu SM. Cadmium-induced hepatotoxicity in rats and the protective effect of naringenin. Exp Toxicol Pathol, 2010; 62: 171-81.

Roopha PD, Padmalatha C. Effect of herbal preparation on heavy metal (Cadmium) induced antioxidant system in female Wistar rats. J Med Toxicol, 2012; 8: 101-07.

Sarkar A, Ravindran G, Krishnamurthy V. A brief review on the effect of cadmium toxicity: from cellular to organ level. Int J Biotechnol Res, 2013; 3:17-36.

Schmidt M, Eisenburg J. Serum bilirubin determination in newborn infants. A new micro-method for the determination of serum of plasma bilirubin in newborn infants. Fortschr Med, 1975; 93:1461-66.

Sinha AK. Colorimetric assay of catalase. Anal Biochem, 1972; 47:389-94

Srinivasan R, Ramprasath C. Beneficial role of silibinin in monitoring the cadmium induced hepatotoxicity in Albino Wistar rats. Rec Res Sci Tech, 2012; 4(1): 46-52.

Varshney R, Kale RK. Effects of calmodulin antagonists on radiation-induced lipid peroxidation in microsomes. Int J Radiat Biol, 1990; 58:733-43.

Walter M, Gerade H. A colorimetric method for determination bilirubin in serum and plasma. Micro Chem J, 1970; 15:231-36.

Zhang T, Hu Y, Tang M, Kong L, Ying J, Wu T, Xue Y, Pu Y. Liver toxicity of cadmium telluride quantum dots (CdTe QDs) due to oxidative stress in vitro and in vivo. Int J Mol Sci, 2015; 16: 23279-299.

\section{How to cite this article:}

Oyinloye BE, Ajiboye BO, Ojo OA, Musa HM, Onikanni SA, Ojo AA. Ameliorative potential of Aframomum melegueta extract in cadmium-induced hepatic damage and oxidative stress in male Wistar rats. J App Pharm Sci, 2016; 6 (07): 094-099. 